\title{
Preschoolers' Concepts of Digestive Physiology and Their Links with Body Mass Index
}

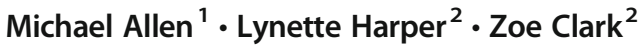

Published online: 25 May 2019

(C) The Author(s) 2019

\begin{abstract}
In this exploratory study, a sample of 20 four-year-olds took part in structured interviews in order to assess their biological knowledge of how the human body processes a food that they perceived to be fattening. There were two main outcomes to the study. First, the sample demonstrated knowledge of the digestive processes of ingestion, digestion/distribution and terminal digestive events that was broadly analogous to previous studies, and included a number of misconceptions. A minority of children could apply biological reasoning to make holistic sense of a series of linked, abstract physiological events. Data also revealed that young learners' models of distribution of food away from the gut might be more sophisticated than previously reported, although none of the sample could provide any mechanism for distribution. Second, data were analysed quantitatively to give performance scores which were compared with children's standardised body mass indices. Children of healthy weight displayed more accurate scientific knowledge of digestive processes than their overweight peers at statistically significant levels. Specifically, the healthy weight children had attained a more holistic understanding of these processes. This potentially has consequences for early years biology education since findings indicate, at a tentative level, that young, overweight children could be considered as having a distinctive special educational need. We propose that there may be a possible way forward for addressing the issues of overweight and obesity in young children by improving their understanding of digestive processes. These outcomes are aligned with calls in the literature for school science education to become more focused on aspects of scientific literacy such as health education. Further studies are recommended using larger samples from more diverse populations.
\end{abstract}

Keywords Preschool $\cdot$ Biological reasoning $\cdot$ Knowledge of nutrition $\cdot$ Body mass index

Michael Allen

m.allen@kingston.ac.uk

1 School of Education, Kingston University, Kingston-upon-Thames, UK

2 School of Nursing, Kingston University, Kingston-upon-Thames, UK 


\section{Introduction}

It is well established that obesity imposes serious risks on a range of health outcomes (World Health Organisation 2017). Driven by a need to address these problems at an early stage, the nutrition, medical, psychology, and health education literatures contain many studies which have examined young children's food-body relationship, generally aimed at promoting the consumption of healthier foods in favour of less healthy alternatives (e.g. Davey et al. 1998; Gripshover and Markman 2013; Hayes-Conroy 2016; Nekitsing et al. 2018). However, there is a dearth of research that has examined what young children believe happens inside their bodies as a result of eating an 'unhealthy' food. The few that do exist report that participants can only verbalise cause-and-effect relationships that are ambiguous or incomplete (Slaughter and Ting 2010).

There have been recent calls in the science education literature for enhancing learners' scientific literacy by means of teaching appropriate concepts and practices of health education (e.g. Arnold 2018; Azevedo and Duarte 2018; Bybee 2012; Byrne and Grace 2018; Crowell and Schunn 2016; Ozbas and Kilinc 2015; Reiss 2015; Zeyer and Dillon 2014). Combined with these are efforts to survey school pupils' ideas of specific health education concepts and create effective interventions (e.g. Acheampong et al. 2003; D’Agostino 2018; Günter and Demir 2018; Hagay and Baram-Tsabari 2011; Mafra et al. 2015; Mallya et al. 2012; Moreno et al. 2018; Reeve and Bell 2009; Romine et al. 2013). The current study's rationale reflects and contributes to this 'healthy science' literature, the broad aim of which is the eventual improvement of health outcomes by considering how science lessons could enhance these particular aspects of scientific literacy. The study helps to address a current deficit in the literature by exploring in some detail preschoolers' ideas of what they think happens to an ingested unhealthy food coupled with an examination of whether these concepts are linked with their body mass index (BMI). The rationale has two facets, each centred on a previously unexplored aspect of science education. The first is to determine the scientific accuracy of the digestive physiology concepts expressed by a sample of preschoolers when they focus solely on a food that they perceive to be fattening. From these responses, their ability to apply biological reasoning can be gauged. Participants' biological knowledge of how the human body processes food has not previously been assessed in these contexts (Mikkelsen et al. 2014). These data act as a precursor for the study's second facet, an investigation of links between these concepts and children's own body development, specifically whether their weight is within healthy or unhealthy limits.

\section{Previous Science Education Research on Young Children's Understandings of Digestive Physiology}

There has been a limited amount of research focused on young children's ideas of digestive processes. ${ }^{1}$ During the early years, these processes are amongst the most-recognised bodily functions (Dempster and Stears 2014; Reiss et al. 2002); for instance, Reiss and colleagues report that an international sample of 7-year-olds frequently included elements of the digestive

\footnotetext{
${ }^{1}$ Colloquially, digestion refers to how the body processes food in a general way, e.g. 'rest after eating is good for digestion'. In the current article, digestion is used in a strictly biological sense, the physical and/or chemical breakdown of ingested food. The more general process is instead termed digestive, e.g. 'the digestive system'.
} 
system when asked to draw what is inside their bodies. Despite this familiarity, several misconceptions have been revealed. Osborne et al. (1992) asked English primary children to draw what happens to ingested food. Some 5-7-year-old drew the interior of the body as a mostly empty vessel storing bits of food - the hollow body model of digestion. Food was not contained in discrete internal organs but instead was distributed within the hollow bag of the body, including arms and legs. However, other 5-7-year-olds did not use a hollow body model and instead drew food contained within a central abdominal area which they called the tummy or belly (ibid.). Similarly, Teixeira's (2000) 4-6-year-old small Brazilian sample $(n=24)$ drew the journey of a bar of chocolate through the body, and many had the food moving from the mouth to a fairly discrete abdominal area (tummy) before being distributed to the legs, which they believed caused stretching of the legs and an increase in the child's height. Toyama's (2000) Japanese 4-5-year-olds also displayed simple ideas of distribution, understanding that food is essential for growth and so becomes part of their bodies.

It has been long established that younger primary children are rarely aware that the body transforms food into simpler forms by means of digestion (e.g. Gellert 1962). They can understand that food is chewed and divided up into smaller pieces but have not yet grasped the idea that food is also changed chemically, being reduced to components that are capable of being absorbed by the body (Carvalho et al. 2004; Osborne et al. 1992; Teixeira 2000). They sometimes believe that food retains its identity within the body, drawing pictures of food that resembles how it looked before it was eaten (Carvalho et al. 2004; Contento 1981; Osborne et al. 1992). Regarding the ultimate fate of food, nearly all of Teixeira's 4-year-olds held a fixed container model where as well as keeping its original identity, once food is ingested, it never leaves the body. Gellert (1962) found that some US primary children thought that defecation was merely a process to stop the body from bursting, and in the same way as Garcia- Barros et al.'s (2011) 4-7-year-old Spanish sample did not link ingested food to egested faeces. In contrast, a recent study found that Czech 5-6-year-olds were readily able to relate eating to defecation, with the researchers suggesting that access to information on the digestive system acquired from computers and tablets was one factor (Adriana and Andrea 2017). Similarly, some of Ahi's (2017) small sample of Turkish 5-year-olds $(n=20)$ thought that ingested food has to leave the body in order to get rid of harmful parts of the food. A common idea displayed by learners of a variety of ages is that solid foods and liquid drinks take different routes through the digestive system (Garcia- Barros et al. 2011; Giordan and Vecchi 1988). Children's ideas develop as they pass through the primary years. For instance, nearly all of Rowlands' (2004) English 10-year-old sample understood that ingested food is physically broken-down during chewing before entering the stomach, some of which is distributed around the body while the remainder is egested.

As well as the specific physiology of the human digestive system, researchers have explored children's ideas of the effects of food on the body in a more general sense. Preschoolers commonly understand that eating is necessary for bodily growth (Endreny 2006; Russell and Watt 1990), that the amount of food a person consumes has an effect on their body size (Schultz and Danford 2016; Slaughter and Ting 2010; Wellman and Johnson 1982) and eating 'good' or 'bad' food can affect their health (Almqvist et al. 2006; Nguyen 2007; Turner 1997; Wellman and Johnson 1982). Nguyen also found that children as young as 3 years can identify photographs of foods as being either junky or healthy, and that junk food was bad for you if you ate too much over a long period. There is some evidence to suggest that preschoolers believe that the quantity of food eaten has a greater effect on growth than whether a food is healthy or otherwise (Slaughter and Ting 2010; Wellman and Johnson 1982). Despite 
this considerable knowledge of the potential effects of food on their health, and an ability to use words such as sugars and fats in appropriate contexts, children younger than 11 years rarely understand the roles that these nutrients play inside the body (e.g. Turner 1997).

\section{Theoretical Framework: Young Children's Cognitive Development}

As summarised in the preceding section, children spontaneously construct their own theories about how their bodies work in the absence of formal teaching; some of these ideas form part of what Carey (1985) calls biological reasoning. She argues that preschool children can only use input-output rules linking isolated pairs of phenomena based on simple observation; for instance, overeating can make a person fat. Any deeper understanding of the underlying physiology, the linking of a sequence of several input-output phenomena holistically, or the ability to construct any causal mechanisms underpinned by biological ideas only appears after 10 years. For example, the body breaks food down which then becomes part of the body itself (ibid.). Younger children instead tend to rely on psychological reasoning e.g. they eat food because it tastes nice (Inagaki and Hatano 2002) or mechanistic reasoning e.g. when they eat food, it allows them to run around (Slaughter and Ting 2010). These views have been challenged, however, by studies that have provided evidence to show that given an appropriate context, preschool children are capable of elements of coherent biological reasoning, linking several input-output relationships, sometimes by utilising abstract concepts (e.g. Keil 1994; Toyama 2000). Relatively few science education researchers have used biological reasoning as a theoretical frame to explain how learners' ideas originate or develop (e.g. Coley and Tanner 2015; Keselman et al. 2015) though some have utilised a preschool sample (e.g. Borgerding and Raven 2018; Christidou and Hatzinikita 2006). This aspect of early years research is important for science education since it helps inform how young children's understanding of cause-and-effect develops in biological contexts, especially in the case of multi-step progressions; this acts as a cornerstone in their future learning of scientific content and process. The current study's first facet relies on the same frame and is focused on an aspect previously unexplored: the extent to which preschoolers can reason biologically in the domain of digestive physiology specifically when considering the different steps undergone when the body deals with a food explicitly labelled as fattening.

Establishing children's concepts was a precursor for the study's second facet - to examine any links between their understanding of digestive processes and BMI. It is established that a lack of general conceptual understanding and BMI are associated; for example, an inverse relationship exists between overweight and children's cognitive function (Yu et al. 2010). Researchers have linked children's eating impulses with cognitive aspects such as memory, verbal abilities, attention, decision-making and executive functioning (cognitive processes governing behaviour). Particularly, executive functioning scores have been found to be inversely related to snack food intake in children and thought to be due to higher-scoring participants having improved emotional eating and inhibitory control skills, although this is likely to be more complex (Pieper and Laugero 2013; Riggs et al. 2010). Therefore, intelligence quotients and educational level could theoretically predict nutrition knowledge that mediates the skills people have to manage their diet (Cabello-Garrido et al. 2017; Halkjær et al. 2003). This view, however, remains contentious (Yu et al. 2010). The current study's second facet was an examination of whether similar links could be found between preschoolers' biological reasoning (which reflects aspects of children's developing executive function) and being overweight. 


\section{Methodology}

Two hypotheses were generated based on the two facets of the theoretical framework, guided by the findings of previous research. The first assumes that some preschoolers would be capable of a degree of coherent biological reasoning as postulated by Keil (1994) and others, and contrasts with Carey's (1985) more age-dependent view. The second hypothesis predicts that executive functioning, as exemplified by biological reasoning, would be associated with preschool children's diet choices thus influencing BMI.

Hypothesis 1: A number of 4-year-old children would possess an ability to reason biologically in the context of digestive physiology.

Hypothesis 2: Four-year-old children's ability to reason biologically in the context of digestive physiology will have an inverse relationship with their body mass index.

Two research questions derived from the hypotheses.

RQ1 How scientifically accurate are the digestive physiology concepts that 4-year-old children exhibit when they explain events that follow the ingestion of a 'fattening' food?

RQ2 Is there a link between 4-year-old children's concepts of human digestive physiology and their body mass indices (BMIs)?

\section{Sample}

An opportunity sample of 20 children aged 4 years \pm 2 months was accrued from four different preschool settings in the southeast of England (mean age $=4$ years 23 days; standard deviation =1.57). The numbers of girls and boys in the sample were statistically equivalent at 9 girls and 11 boys $(p=1.00)$. Table 1 gives full details of the individual children in the sample.

\section{Method}

The method was guided by assumptions and techniques previously employed by the research team with preschool samples (Allen2015, 2017). Because of their developing literacy capabilities, preschoolers typically find it difficult to verbally express their scientific thinking clearly; therefore, it can be more effective to access their thoughts indirectly by making inferences from their binary choices (e.g. Jipson and Gelman 2007). A structured interview schedule was devised where children were asked a series of 13 questions, each requiring either a binary response or a brief answer. Visual cues aid the process by holding young children's attention during the interview (Allen 2017; Prokop et al. 2007), so the questions were asked in combination with an animation presented on a laptop computer that told the story of a character who eats a fattening food (crisps) and wants to know what happens to them inside their body. Question formulation was informed by the different physiological ideas that children can construct, as reported by the studies carried out with preschool samples described in the literature review. Two animations were created that differed only by the character's gender (either Johnny [male] or Julie [female]), each being presented to match to the gender of 


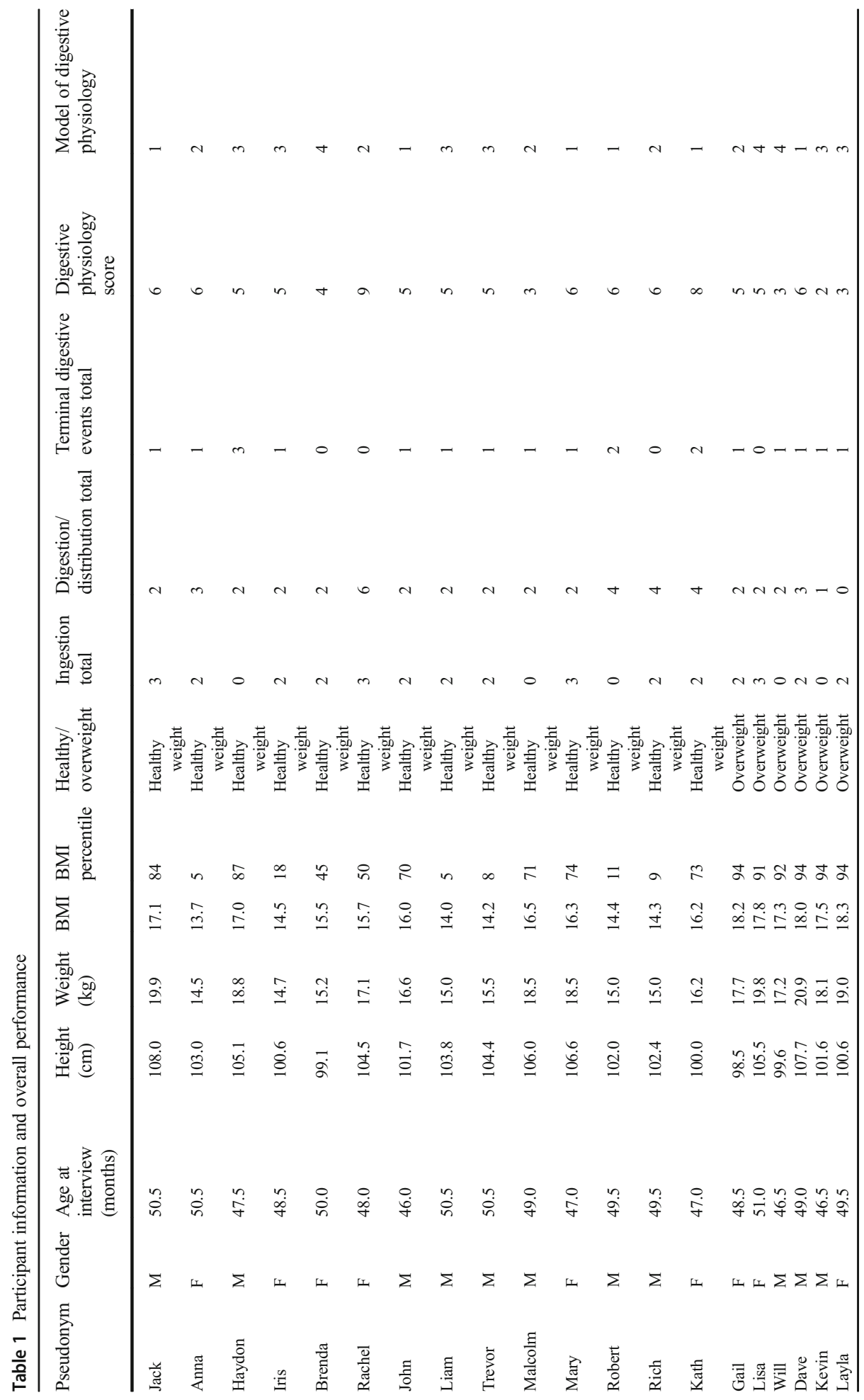


the child being interviewed. Table 2 summarises the schedule; further explanation of each question, including rationales for inclusion, is given below in the analysis section alongside information about how each was coded.

Two researchers conducted each interview; one asked questions from the structured script, while the other recorded the child's binary responses or brief answers ad verbatim using a word processing programme. At the end of the interview, each child's height and weight were measured using a stadiometer and a set of clinical scales by one of the researchers who is a registered nurse, and BMI calculated. Each child's BMI was recorded confidentially using a code number (not the child's name), and these BMI data were kept separately from the interview data to help limit any researcher bias during analysis; the two datasets were only matched after initial coding had been completed.

The study was conducted with appropriate ethical consideration given the young age of the children. Prior to the interviews, informed consent was sought from the children's parents, the managers of the settings, and from the children themselves. The authors' institutional ethics committee had approved the study before the commencement of data collection.

Table 2 Interview questions and comparative performance scores

\begin{tabular}{|c|c|c|c|c|}
\hline $\begin{array}{l}\text { Question } \\
\text { number and } \\
\text { category }\end{array}$ & Question wording & $\begin{array}{l}\text { Healthy } \\
\text { gp \% } \\
\text { correct }\end{array}$ & $\begin{array}{l}\text { Overweight } \\
\text { gp } \% \\
\text { correct }\end{array}$ & $\begin{array}{l}\% \text { difference } \\
\text { (healthy gp minus } \\
\text { overweight gp) }\end{array}$ \\
\hline \multicolumn{5}{|l|}{ Ingestion } \\
\hline 1 & $\begin{array}{l}\text { Do the crisps stay here after he/she swallows } \\
\text { them, or go somewhere else? }\end{array}$ & 78.6 & 66.7 & 11.9 \\
\hline 2 & Where do they go? [Child points on screen] & 78.6 & 66.7 & 11.9 \\
\hline 3 & What is this part of his/her body called? & 21.4 & 16.7 & 4.8 \\
\hline \multicolumn{5}{|c|}{ Digestion/distribution } \\
\hline 4 & $\begin{array}{l}\text { Johnny/Julie wants to know, did the crisps stay in } \\
\text { his/her tummy or go somewhere else in his/her } \\
\text { body? [If they go somewhere else, child points } \\
\text { on screen] }\end{array}$ & 64.3 & 33.3 & 31.0 \\
\hline 5 & $\begin{array}{l}\text { Johnny/Julie wants to know, do the crisps in } \\
\text { his/her tummy look the same as this or are } \\
\text { they different now? }\end{array}$ & 71.4 & 33.3 & 38.1 \\
\hline 6 & $\begin{array}{l}\text { [If they look different] What do they look like } \\
\text { now? }\end{array}$ & 28.6 & 0.0 & 28.6 \\
\hline 7 & $\begin{array}{l}\text { Where will he/she get fat? [Child points on } \\
\text { screen] }\end{array}$ & 78.6 & 83.3 & -4.8 \\
\hline 8 & $\begin{array}{l}\text { Do the crisps stay in his/her tummy or travel to } \\
\text { these parts of the body? }\end{array}$ & 28.6 & 16.7 & 11.9 \\
\hline 9 & $\begin{array}{l}\text { How do the crisps travel from here [tummy] to } \\
\text { these parts of the body? }\end{array}$ & 0.0 & 0.0 & 0.0 \\
\hline 10 & $\begin{array}{l}\text { What do the crisps look like when they are here? } \\
\text { Are they the same as this [crisps picture] or } \\
\text { different? }\end{array}$ & 7.1 & 0.0 & 7.1 \\
\hline \multicolumn{5}{|c|}{ Terminal digestive events } \\
\hline 11 & $\begin{array}{l}\text { Johnny/Julie wakes up the next morning-where } \\
\text { are the crisps now? }\end{array}$ & 28.6 & 16.7 & 11.9 \\
\hline 12 & $\begin{array}{l}\text { Have the crisps stayed in his/her tummy or gone } \\
\text { somewhere else? }\end{array}$ & 14.3 & 16.7 & -2.4 \\
\hline 13 & $\begin{array}{l}\text { [If defecation/toilet is not mentioned] When } \\
\text { Johnny/Julie goes to the toilet, where do the } \\
\text { crisps go? }\end{array}$ & 64.3 & 50.0 & 14.3 \\
\hline
\end{tabular}




\section{Analysis}

\section{Summary of Quantitative Analysis}

The first stage involved determining whether children had answered each of the 13 questions in a scientifically acceptable way. Responses were coded either 1 (correct) or 0 (incorrect); if children did not offer an answer, this was coded as incorrect. The codes were summed so that each child was given a final total (the digestive knowledge score) which reflected how well they understood, as a whole, the digestive physiology concepts tested by the complete set of 13 questions. The set had been divided into three sections that focused on three distinct physiological phases of the digestive process: ingestion (three questions), digestion/distribution (seven questions), and terminal digestive events (three questions). Table 2 gives the questions that were asked within each section.

The ingestion questions tested ideas about where the crisps went immediately after swallowing. Responses were coded as being correct if the child said that the crisps went somewhere else in the body after swallowing (Q1), pointed onto a blank body outline on the computer screen indicating where the food went (Q2) and called this area the tummy, stomach, belly or similar (Q3). With Q2, an acceptable location was considered to be anywhere in the abdomen, i.e. the region beneath the lower ribs and above the pelvis. Although the actual anatomical location of the stomach is the upper left quadrant of the abdomen, colloquially, young children will refer to the stomach, belly or tummy as being situated in a much wider area, anywhere in the abdominal region (Carey 1985); for instance, 'being hit in the stomach', or 'having a tummy ache'.

The set of seven digestion/distribution questions asked children what happens to the crisps after arrival at the stomach and how their appearance might change during this time. First, any misconceptions about food remaining indefinitely in the stomach were elicited by asking whether the crisps go anywhere else apart from the stomach (Q4). The next two questions enquired if the crisps look any different after arrival at the stomach (Q5) and if they did, how they look different (Q6). The remaining four questions in the category centred on whether, where and how crisps might travel away from the stomach. The child was asked to point on the screen to a part of the body that might get fat after eating lots of crisps (Q7), whether crisps travel from the stomach to this place (Q8), details about how they might travel there (Q9) and what the crisps look like once they arrive (Q10). Acceptable responses included that the crisps look different in the stomach; they are smaller/crushed up; eating lots of crisps can make you fat; crisps can travel from the stomach to other parts of the body that become fat; and crisps look different once they get to these parts. Note that although during the process of digestion, food is chemically broken down into simpler molecules and it is in these forms that nutrients are distributed through the body, we kept our questioning focused on the fate of the crisps themselves. Therefore, the assumption was made that if a child understood that crisps could move from the stomach to an area of the body that becomes fat, this was an acceptable protoconcept for the idea of distribution.

The terminal events category consisted of three questions that explored ideas about what happens to ingested food after a period of time has elapsed. To set a familiar context for passing time that the children could understand, we used the situation of going to bed at night and waking up in the morning. Children were first asked where the crisps were when the character had woken up the next morning (Q11) followed by a question about whether they were still in the stomach or had gone somewhere else (Q12). The last question explicitly asked 
if the character goes to the toilet, what happens to the crisps (Q13). If the child said that the crisps had moved away from the stomach this was acceptable because it reflects ideas of distribution, and/or continued passage of the food through the gut. For Q13, only responses that specifically mentioned defecation or food going down the toilet were scored as correct. Table 3 gives exemplar answers, both correct and incorrect, that the children made in response to each of the 13 questions.

Once the three physiology categories had been coded, these were summed so that each child was given a score for each category and then a final digestive knowledge score that was the sum of all three category scores (Table 1). Statistical operations were applied to the digestive knowledge variable which allowed comparisons with other parametric scales; confidence limits for statistical significance were set at 95\%. Student's independent $t$ test assessed possible differences between groups which would infer associations with the parametric variables (typically digestive knowledge) and categorical variables-importantly, children whose BMI percentile lay inside healthy parameters versus other children who were within overweight limits ( $\geq 90$ th percentile). Chi-square test of independence was used to look for

Table 3 Coding exemplars of children's interview responses (italicised text indicates verbatim answers)

\begin{tabular}{|c|c|c|c|}
\hline $\begin{array}{l}\text { Question } \\
\text { number }\end{array}$ & Question wording & Correct response & Incorrect response \\
\hline
\end{tabular}

\begin{tabular}{|c|c|c|c|}
\hline \multicolumn{4}{|c|}{ Ingestion } \\
\hline 1 & $\begin{array}{l}\text { Do the crisps stay here after he/she swallows } \\
\text { them, or go somewhere else? }\end{array}$ & Somewhere else & Stay there \\
\hline 2 & Where do they go? [Child points on screen] & (Points to central abdomen) & $\begin{array}{l}\text { (Points to upper } \\
\text { chest, just left } \\
\text { of the heart) }\end{array}$ \\
\hline 3 & What is this part of his/her body called? & Tummy & Belly button \\
\hline \multicolumn{4}{|c|}{ Digestion/distribution } \\
\hline 4 & $\begin{array}{l}\text { Johnny/Julie wants to know, did the crisps stay } \\
\text { in his/her tummy or go somewhere else in } \\
\text { his/her body? [If they go somewhere else, } \\
\text { child points on screen] }\end{array}$ & $\begin{array}{l}\text { Maybe down his arms and legs } \\
\text { (points to right hand and } \\
\text { right lower leg) }\end{array}$ & Stay in belly \\
\hline 5 & $\begin{array}{l}\text { Johnny/Julie wants to know, do the crisps in } \\
\text { his/her tummy look the same as this or are } \\
\text { they different now? }\end{array}$ & Look different & $\begin{array}{l}\text { Like that (points } \\
\text { to crisps on } \\
\text { screen) }\end{array}$ \\
\hline 6 & $\begin{array}{l}\text { [If they look different] What do they look like } \\
\text { now? }\end{array}$ & Squashed & $\begin{array}{l}\text { (Points to crisps } \\
\text { on screen) }\end{array}$ \\
\hline 7 & $\begin{array}{l}\text { Where will he/she get fat? [Child points on } \\
\text { screen] }\end{array}$ & (Points to central abdomen) & No response \\
\hline 8 & $\begin{array}{l}\text { Do the crisps stay in his/her tummy or travel to } \\
\text { these parts of the body? }\end{array}$ & $\begin{array}{l}\text { Travel go down there (points to } \\
\text { both feet) }\end{array}$ & Stay in tummy \\
\hline 9 & $\begin{array}{l}\text { How do the crisps travel from here [tummy] to } \\
\text { these parts of the body? }\end{array}$ & No correct responses given & Do not know \\
\hline 10 & $\begin{array}{l}\text { What do the crisps look like when they are } \\
\text { here? Are they the same as this [crisps } \\
\text { picture] or different? }\end{array}$ & Something else - squashed & $\begin{array}{l}\text { Look like that } \\
\text { (points to crisps } \\
\text { on screen) }\end{array}$ \\
\hline \multicolumn{4}{|c|}{ Term. digestive events } \\
\hline 11 & $\begin{array}{l}\text { Johnny/Julie wakes up the next } \\
\text { morning - where are the crisps now? }\end{array}$ & Pooed (defecated) & Still in her belly \\
\hline 12 & $\begin{array}{l}\text { Have the crisps stayed in his/her tummy or } \\
\text { gone somewhere else? }\end{array}$ & It's in his poo (faeces) & Do not know \\
\hline 13 & $\begin{array}{l}\text { [If defecation/toilet is not mentioned] When } \\
\text { Johnny/Julie goes to the toilet, where do the } \\
\text { crisps go? }\end{array}$ & Go out of her bum bum (anus) & All in her tummy \\
\hline
\end{tabular}


differences in the ways that individual questions had been answered by children in the different categorical groups (again, mainly BMI percentile groups).

Given the small sample size statistical tests needed to be carefully selected. Independent $t$ testing is an appropriate technique for small sample sizes if other assumptions for validity have been realised. With chi-square if the expected frequency of an input value is less than 5, then the test is not valid, which indeed was the case with some of the calculations we performed, and these were rejected from the analysis. Cohen's d effect size for independent groups was calculated for the variables that compared the two groups and was determined as follows: (higher mean value minus lower mean value) $\div$ standard deviation of the whole sample. Results are presented in Tables 1, 2, 3, and 4 which will be referred to in the 'Results' section.

\section{BMI Percentile Variable}

Body mass index (BMI) is determined by dividing a person's weight $(\mathrm{kg})$ by the square of their height $\left(\mathrm{m}^{2}\right)$. The current study utilised children's BMI percentile values, which is BMI standardised for the age of the child on the day of the interview and gives a more valid unit of analysis than raw BMI values (Royal College of Paediatrics and Child Health 2013). From NHS guidelines (ibid.), the boundaries for children are as follows: underweight $\leq 5$ th percentile; healthy weight 6 th-89th percentile; overweight 90 th -94 th percentile; and obese $\geq 95$ th percentile. With the current sample, 14 children were healthy weight (mean 44th percentile), 6 were overweight (mean 93rd percentile) and none were obese or underweight.

Models of Digestive Physiology Patterns of misconceptions were considered with individual children, specifically if they thought that food does not pass beyond the stomach (Q4) and food is not related to defecation (Q21). Whether individual children displayed one, both or neither of these misconceptions was noted which enabled one of four models of digestive physiology to be allocated to each child (Fig. 1). Any differences in the models held by the healthy weight and overweight groups could then be assessed.

Table 4 A comparison of means of the healthy weight and overweight groups (statistically significant differences are italicised)

\begin{tabular}{|c|c|c|c|c|c|}
\hline & \multicolumn{2}{|c|}{ Mean values } & \multirow{2}{*}{$\begin{array}{l}\text { Statistical } \\
\text { test }\end{array}$} & \multirow{2}{*}{$\begin{array}{l}\text { Statistical probability of } \\
\text { independence }\end{array}$} & \multirow{2}{*}{$\begin{array}{l}\text { Effect } \\
\text { size }\end{array}$} \\
\hline & $\begin{array}{l}\text { Healthy } \\
\text { gp }\end{array}$ & $\begin{array}{l}\text { Overweight } \\
\text { gp }\end{array}$ & & & \\
\hline Ingestion total & 1.8 & 1.5 & $t$ test & 0.60 & 0.27 \\
\hline $\begin{array}{l}\text { Digestion/distribution } \\
\text { total }\end{array}$ & 2.8 & 1.7 & $t$ test & 0.07 & 0.85 \\
\hline $\begin{array}{l}\text { Terminal digestive events } \\
\text { total }\end{array}$ & 1.1 & 0.8 & $t$ test & 0.52 & 0.41 \\
\hline $\begin{array}{l}\text { Digestive physiology } \\
\text { score }\end{array}$ & 5.6 & 4.0 & $t$ test & 0.04 & 0.95 \\
\hline Height & $103.4 \mathrm{~cm}$ & $102.3 \mathrm{~cm}$ & $t$ test & 0.44 & 0.38 \\
\hline Weight & $16.5 \mathrm{~kg}$ & $18.7 \mathrm{~kg}$ & $t$ test & 0.0001 & 1.12 \\
\hline BMI percentile & 43.6 & 91.2 & $t$ test & 0.0001 & 1.33 \\
\hline Age at interview & $48.9 \mathrm{~m}$ & $48.5 \mathrm{~m}$ & $t$ test & 0.63 & 0.25 \\
\hline
\end{tabular}




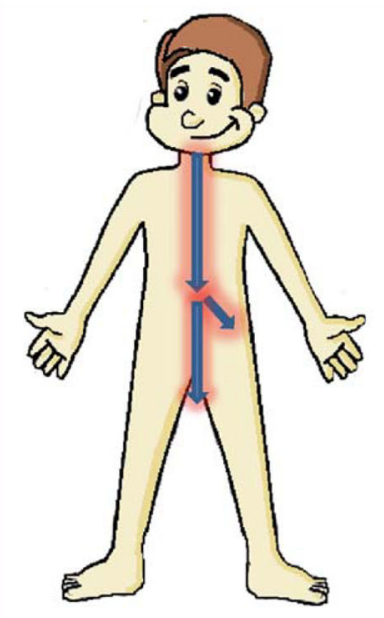

Model 1

(5 healthy weight, 1 overweight)

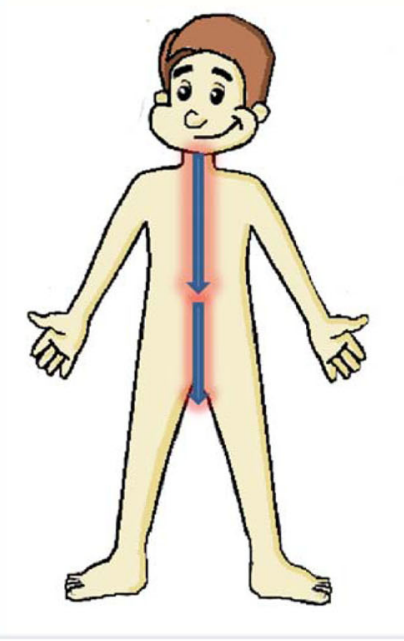

Model 3

(4 healthy weight, 2 overweight)

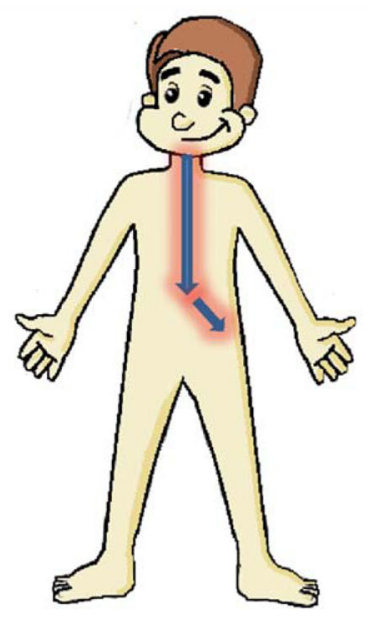

Model 2

(4 healthy weight, 1 overweight)

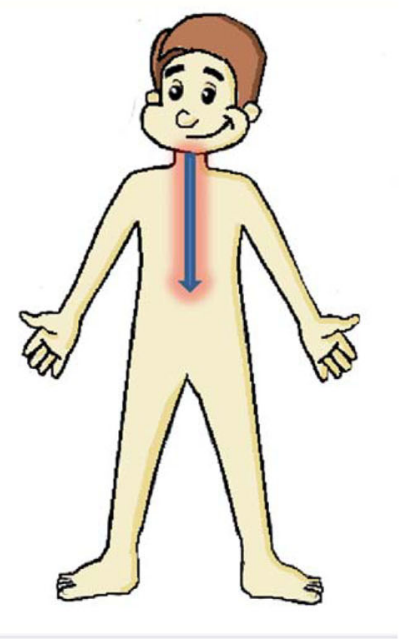

Model 4

(1 healthy weight, 2 overweight)

Fig. 1 Models of digestive physiology

Validity and Reliability Construct validity is the extent to which an instrument is representative of the concepts that it purports to measure; Cohen et al. (2011, p. 188) articulate this as ' $\ldots$ is my understanding of this construct similar to that which is generally accepted to be the construct?'. The interview schedule was assessed by a university senior lecturer in nutrition who confirmed that the set of 13 questions and the assumptions made during their subsequent analysis reflected correct nutritional and biological theory. Face validity is a measure of how interviewees' interpretations of questions correspond to researchers' intended meanings (ibid.). During the extensive piloting of the instrument that took place prior to main data collection, 
questions were repeatedly rephrased and the schedule edited as a result until satisfactory understandings of the questions were forthcoming. Assessing children's responses to the questions, by the end of piloting, we were satisfied that the instrument had good face validity. The reliability of the digestive knowledge scale was difficult to ascertain quantitatively because of low numbers of participants and questions which precluded the use of techniques such as Cronbach's alpha and split halves (Yurdugül 2008). However, an inter-rater reliability process can help assess whether consistency was applied with respect to a particular method of analysis (Cooper and Schindler 2001). This was carried out in the current study as two members of the research team independently coded the data and agreement was $99.9 \%$; this high value was reflective of the structured nature of the interview, children's brief, succinct responses and coding that largely involved making simple binary choices.

\section{Results}

Reflecting the two facets of the research, this section is divided into two sub-sections, each focusing on one of the research questions.

\section{First Facet: RQ1 How Scientifically Accurate Are the Digestive Physiology Concepts That 4-Year-Old Children Exhibit When They Explain Events That Follow the Ingestion of a 'Fattening' Food?}

Children's qualitative responses enabled the identification of a number of specific concepts they held about how the human body deals with food that they perceived as fattening. Data in this sub-section are divided into the three aforementioned categories of digestive physiology and reflect the responses of the sample of 20 children as a whole, regardless of BMI differences. Inferences that consider children's biological reasoning are included later in the discussion chapter.

Ingestion Most children (15/20) said that the crisps would move away from the pharyngeal area after swallowing and could point to an appropriate destination on the animation character's abdominal region. Only four children correctly named the place, calling it the 'tummy' or 'belly'.

Digestion and Distribution Simple concepts of digestion (the physical and chemical breakdown of ingested food) were explored by asking children whether the crisps looked the same inside the stomach compared with before ingestion. A slim majority (12/20) said that they did look different, though only four explained that they had been physically broken up into smaller pieces, mentioning 'crushed', 'crumbs, 'squashed' or 'baby crisps'.

Just over half of the children (11/20) said that the crisps do not stay in the stomach but travel to somewhere else in the body, which indicates an acceptable concept of distribution and/or continued progress through the gut. When asked where food might travel to after being in the stomach, children pointed to either the character's legs, arms or to an area of the abdomen just below where they had previously indicated the stomach to be. Conversely, five children explicitly stated that the crisps stay in the stomach and do not move anywhere else, which we termed the stomach as storehouse model. 
In the current study, the distribution of a food that children perceived to be fattening was an explicit focus and 16/20 children were able to name an appropriate area of the body that might become fat after eating too many crisps, with $12 / 16$ pointing to the abdomen. However, only five children stated that the food was able to travel from the stomach to the area they had pointed out, and none could explain how it arrived there, although one child said that it looked different after arrival- '[They look like] something else, squashed' (Rachel). Therefore, although children were aware that eating too many crisps could make a person fat and that specific parts of the body become fat as a result of eating crisps, none were able to explain in any detail how these two processes were linked in a mechanistic way.

Terminal Digestive Events To represent the passage of several hours, children were told that the character goes to sleep at night and just over half of the children (11/20) said that the crisps were still in his tummy when he woke up the next day. In response to this initial question, only $5 / 20$ gave scientifically acceptable responses which reflected continued distribution, further passage of the food through the gut or egestion (defecation). However, the last question of the category explicitly asked where the crisps go when the character goes to the toilet, and 12/20 cited the process of egestion directly, e.g. 'go out of her bum bum' (Iris) or indirectly, 'down the toilet' (Dave).

\section{Second Facet: RQ2 Is There a Link Between 4-Year-Old Children's Concepts of Human Digestive Physiology and Their Body Mass Indices (BMIs)?}

This subsection summarises quantitative and qualitative data that compare the two groups of children that were the focus of this research question, those of healthy weight and others who were overweight.

\section{Digestive Knowledge Variable}

The descriptive statistics of the digestive knowledge score were as follows: the maximum possible score a child could have achieved was 13, the minimum was zero; with the sample of 20 children, the top score was 9 and the lowest score 2; mean digestive knowledge score was 5.15; and standard deviation was 1.66.

\section{Healthy BMI Percentile Group Vs. Overweight BMI Percentile Group}

The 14 healthy weight children achieved higher digestive knowledge scores than the 6 overweight children to a statistically significant degree, which indicates that they had more scientifically accurate knowledge of the digestive process as a whole $(t=2.26, p<0.05)$. The effect size was 0.95 representing a large effect if sample size is not considered (Cohen 1988). When the healthy and overweight groups' performances were compared question-by-question, which examined whether one group had performed better with each individual item, there were numerical differences. Table 2 gives the percentage correct data each group achieved for each question and also the percentage differences that show comparative performances between the groups. These data indicate that the healthy weight group performed numerically better in 10/ 13 questions, which reflected their superior overall performance in answering the complete set as confirmed by $t$ test. However, when chi-square was applied to test these question-by- 
question differences, none reached statistical significance; low sample size was a factor in these chi-square analyses (note that for brevity, we omitted these analyses from the results tables).

With the three physiology categories of ingestion, digestion/distribution and terminal processes, the healthy weight group scored numerically higher in each category, but these differences did not reach statistical significance. Therefore, although there was a trend with each of the three categories towards the healthy group performing better, the small numbers generated during coding only became statistically significant once the three categories had been combined into an overall final digestive knowledge score. Independent $t$ testing revealed no significant differences between ages of the two groups. Therefore, whether children were in the healthy weight or overweight category was likely to be the determining factor governing their performances. Table 4 summarises the numerical and statistical differences between the two groups.

Ingestion The healthy weight group was $12 \%$ more likely to correctly identify the abdomen as the first destination of swallowed food compared with the overweight group, more of whom did not offer a response.

Digestion and Distribution The healthy weight children displayed more scientifically accurate concepts of how food might be digested or distributed after arrival at the stomach. The healthy weight group was $39 \%$ more likely to understand that physical digestion had taken place and $29 \%$ more likely to accurately describe how the food had changed. There was also a $31 \%$ difference in performance with the healthy group in understanding that the food is distributed away from the stomach. There was a slight difference with the overweight group (4\%) in naming a part of the body that might become fat after eating too many crisps. Both groups achieved their highest scores in this category.

Terminal Digestive Events The healthy weight group were $14 \%$ more likely to state that the food exited the body through defecation than the overweight group; therefore, a fixed container model was numerically more prevalent with the overweight group. In addition, the healthy weight group were $12 \%$ more likely to use correct models of distribution, further passage of the food through the gut or defecation to explain digestive events after a night of sleep.

Models of Digestive Physiology To further investigate differences between the thinking of heathy weight and overweight groups, it is possible to compare different models of digestive physiology. Two physiology misconceptions were apparent from the data, the stomach as storehouse and fixed container models. Only three children displayed both misconceptions; others in the sample displayed either one misconception plus one correct idea (11 children), or two correct ideas (six children). Therefore, there was no single model of digestive physiology that emerged from the data; instead, there was a more nuanced situation (Fig. 1). Model 1 depicts a biologically correct view of both distribution and egestion (five healthy weight, one overweight). Note, however, that although most children could understand that fattening food in the stomach causes specific parts of the body to become fat, only five explicitly stated that food was able to travel from the stomach to a fatty part of the body. Model 2 shows a correct concept of distribution alongside a fixed container misconception (four healthy weight, one overweight). Model 3 shows a stomach as storehouse misconception coupled with correct 
egestion (four healthy weight, two overweight). Model 4 depicts the two misconceptions held concurrently (one healthy weight, two overweight). More of the overweight group held at least one of the two key misconceptions compared with the healthy weight group (83\% vs. 64\%) although numbers were too small to show statistical significance.

\section{Discussion}

As with the 'Results' section, the discussion is organised into two sub-sections reflecting the different facets of the study and then further divided into the three aspects of digestive physiology.

\section{First Facet: RQ1 How Scientifically Accurate Are the Digestive Physiology Concepts That 4-Year-Old Children Exhibit When They Explain Events That Follow the Ingestion of a 'Fattening' Food?}

Ingestion The data concur with previous findings which have determined that young children tend to be aware that ingested food travels down to a discrete area in the abdomen (Osborne et al. 1992; Teixeira 2000). Data from some previous studies instead show food distributing itself freely throughout the body - the hollow body model (Carvalho et al. 2004; Cubero 1998; Osborne et al. 1992). The more general and less precise nature of the questions asked during these last three studies means that it is difficult to determine whether children who drew the hollow body model incorrectly believed that ingested food distributes itself widely immediately after ingestion and does not pass through a discrete area (stomach) or that they correctly considered longer-term processes of distribution after food has reached the stomach. We would suggest the latter, not least because it makes sense to expect that most preschoolers would be able relate ingested food to their stomach region; for instance, they rub their tummies when they are thinking about nice food or after a satisfying meal. With the current study, the hollow body model was absent. The validity of the three previous studies is not in question, though one difference of the current data was the more precise nature of the questions that meant that during analysis, it was straightforward to differentiate between children's ideas of ingestion and distribution. Some young children seem able to understand that 'food' travels to different parts of the body for growth to take place (e.g. Teixeira 2000). Therefore, we argue that a hollow body model may not necessarily reflect misconceptions but may instead be a valid view of longer-term distribution of food throughout the body.

Carey (1985) posited that preschool children are capable of stating simple input-output rules to link pairs of phenomena; that was certainly the case with the current study, for instance, ingesting food $\rightarrow$ food ends up in the stomach. Other data presented in the current article shows that this reasoning sometimes went beyond pairing two phenomena, with children able to think more holistically about a series of linked digestive processes. It might be thought that the precise nature of the questions in the current study and the fact that they were asked in the same order as real digestive events may have driven children's thinking towards a scientifically accurate direction that cued them to give responses that correctly linked a chain of events. One disadvantage of structured interviews compared with more open approaches is that the constructs of the researcher might influence responses i.e. in the case of the current study, the order that questions were presented. However, although questions 
were asked that reflected the correct order of events, at each step, children were presented with free choices, mostly binary in nature, that allowed them to give responses that deviated from scientific accuracy, as many did. In this context, we see the linear aspect of the questioning as a strength since it enabled us to determine whether a child had understood a single digestive process in a very specific way. If they were also able to show correct understanding with preceding and/or subsequent processes, then this demonstrates an ability to mentally follow a piece of food as it passes through several stages of digestion which represents holistic biological reasoning.

Digestion and Distribution The children's responses align with previous studies that have revealed that young children do not always understand that food undergoes physical or chemical transformation inside the body (Contento 1981; Gellert 1962; Gripshover and Markman 2013; Osborne et al. 1992) and that young children's knowledge of events after food reaches the stomach is vague (Contento 1981; Teixeira 2000). That said, as was the case with a number of Teixeira's 4-year-olds, a minority of children in the current study were able to explain that food was distributed from the stomach to other parts of the body reflecting a correct model of distribution. This supports the aforementioned view that the hollow body model as reported by previous studies might reflect a scientifically correct idea of distribution.

Terminal Digestive Events These data echo previous studies that have established that preschool samples can link eating with defecation (Adriana and Andrea 2017; Ahi 2017) although it is noted that other studies have found no such association, with most/all children holding a fixed container model (Garcia- Barros et al. 2011; Gellert 1962; Teixeira 2000).

\section{Second Facet: RQ2 Is There a Link Between 4-Year-Old Children's Concepts of Human Digestive Physiology and Their Body Mass Indices (BMIs)?}

The second facet of the study involved quantitative and qualitative comparisons between the digestive concepts of children in the healthy weight group vs. those in the overweight group. The healthy weight group performed better than the overweight group to statistically significant levels when answering the complete set of 13 questions (digestive physiology variable) which indicated that they had a more complete, holistic knowledge of the digestive process overall. These better performances by the healthy weight group are summarised in Table 2 where percent differences regarding individual questions are given. It is important to note, however, in contrast to overall performance with the question set as a whole, no difference with respect to any individual question reached statistical significance between the two groups. This may have been due to the low numbers available when undertaking statistical operations with the individual questions (the numbers were larger with the overall digestive knowledge variable). That said, the qualitative comparisons given in the results and discussion sections help offer some insight into how the thinking of the healthy weight children differed from those in the overweight group.

Numerically, both groups achieved their best scores with digestion/distribution concepts (Table 4). This was especially the case with the healthy children, which made this category present the biggest difference in knowledge between the two groups. Therefore, the overweight children were less likely to understand what happens to food once it reaches the stomach, and with a larger sample, the stomach as storehouse model might have been more prevalent in this group to a statistically significant degree. 


\section{Conclusions}

In relation to the first facet of the theoretical frame, the study determined children's qualitative ideas about digestive processes taking place after the ingestion of a food that had been explicitly labelled as fattening, an aspect previously unexplored. Despite this differential focus, children's concepts were broadly analogous to those reported in the literature using preschool samples apart from a complete absence of the hollow body misconception in the current study, thought due to methodological differences between this and previous research. We propose that when considering children's models of the distribution of food, a hollow body model could in fact indicate a correct concept of distribution. Considering the literature from this fresh perspective, it might be the case that more young learners than previously realised have understood that food first enters the stomach and then is distributed away. Children in the current study were, however, unable to suggest any mechanisms of distribution.

Most children in the current study were able to express scientifically acceptable concepts of ingestion, distribution and/or terminal digestive events, which reflects the findings of some previous studies. Carey (1985) asserts that preschool children, although capable of making isolated input-output relationships, cannot yet construct coherent, naïve theories based on biological understandings of how the body works. This view has been challenged by others who have found the contrary (e.g. Inagaki and Hatano 2006; Morris et al. 2000). As reflected in our first hypothesis, the minority of children in the current study who attained higher digestive knowledge scores had a more complete, holistic appreciation of the overall digestive process which went beyond isolated input-output pairing of phenomena and indicated a level of biological reasoning that took into account multi-step cause-and-effect relationships. Just over a quarter revealed an appreciation of several separate, abstract physiological events that showed elements of this level of biological thinking (model 1;6/20 children). In these respects, the findings add to those uncovered by the few studies of preschool biological reasoning in science education (e.g. Christidou and Hatzinikita 2006) and challenge the assertions of Carey and others. This small body of prior research informs future planning that determines the ages at which particular science ideas are first introduced to children. If they are shown to be capable of applying reasoning at higher levels than previously determined (especially when linking cause-and-effect in more sophisticated ways), acceleration of science programmes might be considered.

Considering the theoretical frame's second facet, data from the first facet acted as a precursor. We hypothesised that there would be an inverse link between the level of biological reasoning and BMI. This was confirmed since data indicated that the healthy weight group's overall performance was higher than that of the overweight group at a statistically significant level, although when individual questions were analysed, there were no statistical differences (thought to be due to low numbers). However, there were qualitative differences in thinking between the two groups relating to the three digestive processes, but because these differences did not reach statistical significance, inferences must remain tentative.

Previous studies have found that overweight and obese preschool children tend to have less developed reasoning abilities than their peers, arguing that a lower cognitive ability, specifically a reduced facility of executive function, is causative for overweight (e.g. Guxens et al. 2009; Pieper and Laugero 2013). A cause-and-effect relationship could occur due to the two different areas of the brain that govern executive function and food intake, both having pathology that results in dysfunction; consequently, the child scores less in cognitive tests and also consumes more food than peers (Guxens et al. 2009). Taken in light of the current 
findings, this would mean a reason why the overweight children performed less well was because their brain hierarchy is different, perhaps innately so. It follows that since the overweight group was generally not able to use biological reasoning at the same level as their peers of healthy weight, they would potentially be more likely to construct the stomach as storehouse and fixed container models.

However, considering the current data, the direction of cause-and-effect might be in the reverse direction. Caird et al. (2011), in their literature review on obesity and educational attainment, report that studies commonly conclude that the fact of being obese per se is sufficient to cause a child to perform poorly educationally. This is due to their obesity creating '...poor mental health, stigmatisation and discrimination, disordered sleep, decreased time spent in physical activity and socialising, and absenteeism' (ibid. p. 10). This would mean that being overweight acted as a barrier to the children's science learning, not any innate deficiency in cognitive ability.

\section{Limits of the Study}

The sample of 20 was too small to be representative of any larger population, although the four early years settings used were diverse which meant that children from a variety of different socioeconomic and cultural areas took part. This small size limits confidence if one was to generalise the study's conclusions more widely, though since statistical tests were significant even with such low numbers, this could indicate that the associations were powerful. The methodology that was chosen did not allow us to determine the direction of any cause-andeffect relationship between physiological knowledge and overweight. In fact, only a long-term longitudinal study perhaps lasting several years that tracks conceptual understanding and BMI could properly establish this. Mindful of these limitations, we recommend that further research, conceivably carried out over an extended period, and uses larger samples that can be more representative of a population be considered.

\section{Implications}

There have been calls in the recent science education literature to improve conceptual understanding of digestive processes, helping to educate learners and reduce the likelihood of unhealthy weight gain (e.g. Ozbas and Kilinc 2015). Note that with the current study, the two possible reasons for the link between digestive knowledge and overweight, i.e. that children apply biological reasoning at a reduced level resulting in overweight, or being overweight itself causes reduced biological reasoning, would be mutually exclusive since they represent opposite directionalities in any cause-and-effect model. However, both have similar implications for science teaching and learning in that a solution would be for learners to better understand concepts of digestive physiology. If a reduced ability to reason biologically is causative of overweight, then the brain hierarchy of overweight children would be different, and there is an argument for them being categorised as having a distinctive special educational need at the preschool stage. The same would apply if causation was in the other direction since the physical experience of being overweight makes it more likely that misconceptions would be constructed. In either case, specialised programmes of healthy nutrition that are already taking place in early years settings could be supplemented with interventions that focus 
specifically on children learning scientific concepts of digestive physiology that refute the stomach as storehouse and fixed container misconceptions. It might be the case that learning correct biological concepts will help overweight children realise that the quality and quantity of food that they eat are directly related to their own body development.

All this considered, meta-analyses indicate that multi-tiered approaches to combat childhood obesity which include influencing policy and the family in parallel with education are what is required (Ling et al. 2017; Ozbas and Kilinc 2015; van Hoek et al. 2014; Williams et al. 2013). Educating the families of overweight children is especially important since many of their food choices would mirror those of parents, although children themselves do exert some control about the quantity of food they eat. The literature currently provides a lack of clarity as to precisely the material that educational approaches should include. However, we believe that more work needs to be done to determine the different ways that overweight children conceptualise how their bodies deal with food. Most nutrition research in the health education domain aims to inform children's dietary programmes, but we argue that appropriate physiology concept development in the early years, informed by the findings of science education, may also help provide a fruitful way forward.

Open Access This article is distributed under the terms of the Creative Commons Attribution 4.0 International License (http://creativecommons.org/licenses/by/4.0/), which permits unrestricted use, distribution, and reproduction in any medium, provided you give appropriate credit to the original author(s) and the source, provide a link to the Creative Commons license, and indicate if changes were made.

\section{References}

Acheampong, R., Woolfe, J., \& Levy, L. (2003). Encouraging consumption of fruit and vegetables by young people through school-based interventions. Journal of Biological Education, 37(3), 122-125.

Adriana, W., \& Andrea, D. (2017). How food is processed in the human body or children's concepts of how the digestive system works. Procedia-Social and Behavioral Sciences, 237(1), 1582-1587.

Ahi, B. (2017). Thinking about digestive system in early childhood: A comparative study about biological knowledge. Cogent Education, 4(1), 1278650.

Allen, M. (2015). Preschool children's taxonomic knowledge of animal species. Journal of Research in Science Teaching 52(1), 107-134.

Allen, M. (2017). Early understandings of simple food chains: A learning progression for the preschool years. International Journal of Science Education 39(11), 1485-1510.

Almqvist, L., Hellnäs, P., Stefansson, M., \& Granlund, M. (2006). 'I can play!' young children's perceptions of health. Pediatric Rehabilitation, 9(3), 275-284.

Arnold, J. C. (2018). An integrated model of decision-making in health contexts: The role of science education in health education. International Journal of Science Education, 40(5), 519-537.

Azevedo, M. M., \& Duarte, S. (2018). Continuous enhancement of science teachers' knowledge and skills through scientific lecturing. Frontiers in Public Health, 6, 41.

Borgerding, L. A., \& Raven, S. (2018). Children's ideas about fossils and foundational concepts related to fossils. Science Education, 102(2), 414-439.

Bybee, R. W. (2012). Scientific literacy in environmental and health education. In A. Zeyer \& R. Kyburz-Graber (Eds.), Science | environment | health: Towards a renewed pedagogy for science education (pp. 49-67). Dordrecht: Springer.

Byrne, J., \& Grace, M. (2018). Health and disease. In K. Kampourakis \& M. J. Reiss (Eds.), Teaching biology in schools (pp. 74-86). New York: Routledge.

Cabello-Garrido, A., Espana-Ramos, E., \& Lopez, B. (2017). Developing a human nutrition learning progression. International Journal of Science and Mathematics Education, 1-21.

Caird, J., Kavanagh, J., Oliver, K., Oliver, S., O'Mara, A., Stansfield, C., \& Thomas, J. (2011). Childhood obesity and educational attainment: A systematic review. London: Institute of Education, University of London.

Carey, S. (1985). Conceptual change in childhood. Cambridge: Bradford. 
Carvalho, G. S., Silva, R., Lima, N., Coquet, E., \& Clément, P. (2004). Portuguese primary school children's conceptions about digestion: Identification of learning obstacles. International Journal of Science Education, 26(9), 1111-1130.

Christidou, V., \& Hatzinikita, V. (2006). Preschool children's explanations of plant growth and rain formation: A comparative analysis. Research in Science Education, 36(3), 187-210.

Cohen, J. (1988). Statistical power analysis for the behavioral sciences (2nd ed.). Hillsdale: Erlbaum.

Cohen, L., Manion, L., \& Morrison, K. (2011). Research methods in education (7th ed.). Abingdon: Routledge.

Coley, J. D., \& Tanner, K. (2015). Relations between intuitive biological thinking and biological misconceptions in biology majors and nonmajors. CBE-Life Sciences Education, 14(1), ar8.

Contento, I. (1981). Children's thinking about food and eating: A Piagetian-based study. Journal of Nutrition Education, 13(1), S86-S90.

Cooper, D. R., \& Schindler, P. S. (2001). Business research methods (7th ed.). New York: McGraw-Hill.

Crowell, A., \& Schunn, C. (2016). Unpacking the relationship between science education and applied scientific literacy. Research in Science Education, 46(1), 129-140.

Cubero, R. (1998). La construcción del conocimiento del proceso digestive: Un estudio longitudinal (The construction of knowledge of the digestive process: A longitudinal study). In E. Banet \& A. De Pro (Eds.), Investigacióne Innovación en la Enseñanza de las Ciencias (Research and Innovation in the Teaching of Sciences). Murcia: DM.

D’Agostino, E. (2018). Public health education: Teaching epidemiology in high school classrooms. American Journal of Public Health, 108(3), 324-328.

Davey, G. C., Buckland, G., Tantow, B., \& Dallos, R. (1998). Disgust and eating disorders. European Eating Disorders Review: The Professional Journal of the Eating Disorders Association, 6(3), 201-211.

Dempster, E., \& Stears, M. (2014). An analysis of children's drawings of what they think is inside their bodies: A south African regional study. Journal of Biological Education, 48(2), 71-79.

Endreny, A. H. (2006). Children's ideas about animal adaptations: An action research project. Journal of Elementary Science Education, 18(1), 33-42.

Garcia- Barros, S., Martínez-Losada, C., \& Garrido, M. (2011). What do children aged four to seven know about the digestive system and the respiratory system of the human being and of other animals? International Journal of Science Education, 33, 2095-2122.

Gellert, E. (1962). Children's conceptions of the content and functions of the human body. Genetic Psychology Monographs, 65, 293-405.

Giordan, A., \& Vecchi, G. (1988). Los Orígenes del Saber. Sevilla: Ed. Diada.

Gripshover, S. J., \& Markman, E. M. (2013). Teaching young children a theory of nutrition: Conceptual change and the potential for increased vegetable consumption. Psychological Science, 24(8), 1541-1553.

Günter, T., \& Demir, F. E. O. (2018). The effect of using a case study on the academic achievement of students in learning about the topic of 'vitamins'. Journal of Biological Education 53(3), 288-301.

Guxens, M., Mendez, M. A., Julvez, J., Plana, E., Forns, J., Basagana, X., Torrent, M., \& Sunyer, J. (2009). Cognitive function and overweight in preschool children. American Journal of Epidemiology, 170(4), 438446.

Hagay, G., \& Baram-Tsabari, A. (2011). A shadow curriculum: Incorporating students' interests into the formal biology curriculum. Research in Science Education, 41(5), 611-634.

Halkjær, J., Holst, C., \& Sørensen, T. I. (2003). Intelligence test score and educational level in relation to BMI changes and obesity. Obesity, 11(10), 1238-1245.

Hayes-Conroy, A. (Ed.). (2016). Doing Nutrition Differently: Critical Approaches to Diet and Dietary Intervention. Abingdon: Routledge.

Inagaki, K., \& Hatano, G. (2002). Young Children's intuitive thinking about the biological world. New York: Psychology Press.

Inagaki, K., \& Hatano, G. (2006). Young children's conception of the biological world. Current Directions in Psychological Science, 15, 177-181.

Jipson, J. L., \& Gelman, S. A. (2007). Robots and rodents: Children's inferences about living and non-living things. Child Development, 78, 1675-1688.

Keil, F. C. (1994). The birth and nurturance of concepts by domains: The origins of concepts of living things. In L. A. Hirschfeld \& S. A. Gelman (Eds.), Mapping the mind: Domain specificity in cognition and vulture (pp. 234-254). Cambridge: Cambridge University Press.

Keselman, A., Hundal, S., Chentsova-Dutton, Y., Bibi, R., \& Edelman, J. A. (2015). The relationship between biology classes and biological reasoning and common heath misconceptions. The American Biology Teacher, 77(3), 170-175.

Ling, J., Robbins, L., Wen, F., \& Zhang, N. (2017). Lifestyle interventions in preschool children: A meta-analysis of effectiveness. American Journal of Preventative Medicine, 53(1), 102-112. 
Mafra, P., Lima, N., \& Carvalho, G. S. (2015). Experimental activities in primary school to learn about microbes in an oral health education context. Journal of Biological Education, 49(2), 190-203.

Mallya, A., Mensah, F. M., Contento, I. R., Koch, P. A., \& Barton, A. C. (2012). Extending science beyond the classroom door: Learning from students' experiences with the choice, control and change (C3) curriculum. Journal of Research in Science Teaching, 49(2), 244-269.

Mikkelsen, M., Husby, S., Skov, L., \& Perez-Cueto, F. (2014). A systematic review of types of healthy eating interventions in preschools. Nutrition Journal, (56), 13.

Moreno, N. P., Newell, A. D., Zientek, L. R., Nimon, K., \& Vogt, G. L. (2018). Linking science education and HIV using viral biology, epidemiology and science practices. Health Education Journal 77(8), 884-898.

Morris, S. C., Taplin, J. E., \& Gelman, S. A. (2000). Vitalism in naïve biological thinking. Developmental Psychology, 36(5), 582-595.

Nekitsing, C., Blundell-Birtill, P., Cockroft, J. E., \& Hetherington, M. M. (2018). Systematic review and metaanalysis of strategies to increase vegetable consumption in preschool children aged 2-5 years. Appetite, 127, 138-154.

Nguyen, S. (2007). An apple a day keeps the doctor away: Children's evaluative categories of food. Appetite, 48, 114-118.

Osborne, J. F., Wadsworth, P., \& Black, P. J. (1992). SPACE research report: Processes of life. Liverpool: Liverpool University Press.

Ozbas, S., \& Kilinc, A. (2015). School students' conceptual patterns about weight gain: A preliminary study for biology teaching focusing on obesity. Journal of Biological Education, 49(4), 339-353.

Pieper, J. R., \& Laugero, K. D. (2013). Preschool children with lower executive function may be more vulnerable to emotional-based eating in the absence of hunger. Appetite, 62, 103-109.

Prokop, P., Prokop, M., Tunnicliffe, S. D., \& Diran, C. (2007). Children's ideas of animals' internal structures. Journal of Biological Education, 41, 62-67.

Reeve, S., \& Bell, P. (2009). Children's self-documentation and understanding of the concepts 'healthy' and 'unhealthy'. International Journal of Science Education, 31(14), 1953-1974.

Reiss, M. J. (2015). Health science education in primary schools: Evaluation of procedures and results. In, Giuseppe, M. (ed.)Proceedings of the International Workshop on Health Science Education in Primary Schools (Vol. 2015). May, 2015, Rome, Italy: Atti dei Convegni Lincei.

Reiss, M. J., Tunnicliffe, S. D., Bartoszeck, A., Carvalho, G., Chen, S., Jarman, R., Jonsson, S., Manokore, V., Marchenko, N., Mulemwa, J., Novikova, T., Otuka, J., Teppa, S., \& Rooy, W. (2002). An international study of young peoples' drawings of what is inside themselves. Journal of Biological Education, 36(2), 58-64.

Riggs, N. R., Spruijt-Metz, D., Sakuma, K. L., Chou, C. P., \& Pentz, M. A. (2010). Executive cognitive function and food intake in children. Journal of Nutrition Education and Behaviour, 42(6), 398-403.

Romine, W. L., Barrow, L. H., \& Folk, W. R. (2013). Exploring secondary students' knowledge and misconceptions about influenza: Development, validation, and implementation of a multiple-choice influenza knowledge scale. International Journal of Science Education, 35(11), 1874-1901.

Rowlands, M. (2004). What do children think happens to the food they eat? Journal of Biological Education, 38(4), 167-171.

Royal College of Paediatrics and Child Health (2013). Body Mass Index (BMI) Chart. https://www.rcpch.ac. uk/child-health/research-projects/uk-who-growth-charts/uk-growth-chart-resources-2-18-years/schoolage\#bmi. Accessed 16th March 2018.

Russell, T., \& Watt, D. (1990). SPACE research report: Growth. Liverpool: Liverpool University Press.

Schultz, C. M., \& Danford, C. M. (2016). Children's knowledge of eating: An integrative review of the literature. Appetite, 1(107), 534-548.

Slaughter, V., \& Ting, C. (2010). Development of ideas about food and nutrition from preschool to university. Appetite, 55(3), 556-564.

Teixeira, F. M. (2000). What happens to the food we eat? Children's conceptions of the structure and function of the digestive system. International Journal of Science Education, 22(5), 507-520.

Toyama, N. (2000). What are food and air like inside our bodies?: Children's thinking about digestion and respiration. International Journal of Behavioral Development, 24(2), 222-230.

Turner, S. A. (1997). Children's understanding of food and health in primary classrooms. International Journal of Science Education, 19(5), 491-508.

van Hoek, E., Feskens, E. J., Bouwman, L. I., \& Janse, A. J. (2014). Effective interventions in overweight or obese young children: Systematic review and meta-analysis. Childhood Obesity, 10(6), 448-460.

Wellman, H. M., \& Johnson, C. N. (1982). Children's understanding of food and its functions: A preliminary study of the development of concepts of nutrition. Journal of Applied Developmental Psychology, 3(2), 135148.

Williams, A. J., Henley, W. E., Williams, C. A., Hurst, A. J., Logan, S., \& Wyatt, K. M. (2013). Systematic review and meta-analysis of the association between childhood overweight and obesity and primary school 
diet and physical activity policies. International Journal of Behavioural Nutrition and Physical Activity, $10(1), 101$.

World Health Organisation. (2017). Report of the Commission on Ending Childhood Obesity: Implementation Plan, Executive Summary. Geneva: World Health Organisation.

Yu, Z. B., Han, S. P., Cao, X. G., \& Guo, X. R. (2010). Intelligence in relation to obesity: A systematic review and meta-analysis. Obesity Reviews, 11(9), 656-670.

Yurdugül, H. (2008). Minimum sample size for Cronbach's coefficient alpha: A Monte-Carlo study. Hacettepe Üniversitesi Eğitim Fakültesi Dergisi (Hacettepe University education faculty magazine), 35(35), 1-9.

Zeyer, A., \& Dillon, J. (2014). Science | environment $\mid$ health: Towards a reconceptualization of three critical and inter-linked areas of education. International Journal of Science Education, 36(9), 1409-1411.

Publisher's Note Springer Nature remains neutral with regard to jurisdictional claims in published maps and institutional affiliations. 